Southern Illinois University Carbondale

OpenSIUC

Publications

Department of Physics

4-1-2012

\title{
Magnetic and Magnetocaloric Properties of the New Rare-Earth-Transition-Metal Intermetallic Compound Gd3Co29Ge4B10
}

P. Hill

Southeast Missouri State University

Igor Dubenko

Southern Illinois University Carbondale

Tampas Samanta

Southern Illinois University Carbondale

Abdiel Quetz

Southern Illinois University Carbondale

Naushad Ali

Southern Illinois University Carbondale

Follow this and additional works at: http://opensiuc.lib.siu.edu/phys_pubs

(C) 2012 American Institute of Physics

Published in Journal of Applied Physics, Vol. 111 No. 7 (2012) at doi: 10.1063/1.3677658

\section{Recommended Citation}

Hill, P., Dubenko, Igor, Samanta, Tampas, Quetz, Abdiel and Ali, Naushad. "Magnetic and Magnetocaloric Properties of the New RareEarth-Transition-Metal Intermetallic Compound Gd3Co29Ge4B10." (Apr 2012).

This Article is brought to you for free and open access by the Department of Physics at OpenSIUC. It has been accepted for inclusion in Publications by an authorized administrator of OpenSIUC. For more information, please contact opensiuc@lib.siu.edu. 


\title{
Magnetic and magnetocaloric properties of the new rare-earth-transition- metal intermetallic compound $\mathrm{Gd}_{3} \mathrm{Co}_{29} \mathrm{Ge}_{4} \mathrm{~B}_{10}$
}

\author{
P. Hill, ${ }^{1, a)}$ Igor Dubenko, ${ }^{2}$ Tapas Samanta, ${ }^{2}$ Abdiel Quetz, ${ }^{2}$ and Naushad $\mathrm{Ali}^{2}$ \\ ${ }^{1}$ Department of Physics and Engineering Physics, Southeast Missouri State University, Cape Girardeau, \\ Missouri 63701, USA \\ ${ }^{2}$ Department of Physics, Southern Illinois University-Carbondale, Carbondale, Illinois 62901, USA
}

(Presented 1 November 2011; received 23 September 2011; accepted 15 November 2011; published online 7 March 2012)

\begin{abstract}
The compounds $\mathrm{Gd}_{3-x} \mathrm{Y}_{x} \mathrm{Co}_{29} \mathrm{Ge}_{4} \mathrm{~B}_{10}\left(x=0,0.5,1.0,1.5\right.$, and 3.0), $\mathrm{Gd}_{3} \mathrm{Co}_{29} \mathrm{Al}_{4} \mathrm{~B}_{10}$, and $\mathrm{Gd}_{3} \mathrm{Co}_{29} \mathrm{Al}_{4} \mathrm{~B}_{10}$ were synthesized by arc melting, and their magnetic properties investigated as a function of temperature and applied magnetic field. X-ray measurements showed primarily singlephase samples with the tetragonal crystal structure P4/nmm. It was found that $\mathrm{Gd}_{3} \mathrm{Co}_{29} \mathrm{Ge}_{4} \mathrm{~B}_{10}$ orders ferromagnetically at $T_{C}=212 \mathrm{~K}$ and shows a compensation point at $128 \mathrm{~K}$, indicating a ferrimagnetic ordering of the Co and Gd moments. An entropy change of $-\Delta S=0.5 \mathrm{~J} / \mathrm{kgK}$ was observed in a 5-T field at $T_{C}$ for this sample, while a change in sign for this quantity was observed both at the maximum value of magnetization (around $200 \mathrm{~K}$ ) and then again at the compensation point. Substitution of $\mathrm{Y}$ for $\mathrm{Gd}$ in $\mathrm{Gd}_{3} \mathrm{Co}_{29} \mathrm{Ge}_{4} \mathrm{~B}_{10}$ does not affect the Curie temperature, but shifts the compensation point to lower temperatures. This indicates that a decrease in Gd concentration does not affect the $d$ - $d$ exchange interaction, but has a pronounced effect on the $f$ - $d$ exchange interaction. (C) 2012 American Institute of Physics. [doi:10.1063/1.3677658]
\end{abstract}

\section{INTRODUCTION}

Recently, substantial work has been done on the structural properties of the new family of the stable rare-earthtransition-metal compounds $R_{3} T_{29} M_{4} \mathrm{~B}_{10} \quad(R=$ rare earth (except $\mathrm{Yb}, \mathrm{Pm}$, and $\mathrm{Eu}$ ), $T=\mathrm{Co}, \mathrm{Ni}$, and $M=\mathrm{Si}, \mathrm{Ge}, \mathrm{Al}$ ). ${ }^{3,4}$ These samples crystallize in the $P 4 / \mathrm{nmm}$ tetragonal structure. Much of the recent experimental and theoretical work has explored the interesting and complex magnetic behavior of these samples, focusing on the influence of various rare earths on the magnetic properties of samples in the Si family of compounds. ${ }^{1,2,4-6}$ These materials order with ferrimagnetic coupling between the heavy rare-earth and cobalt lattices. ${ }^{7}$ Here we investigate the influence of substituting a nonmagnetic element, yttrium, on the rare-earth site.

\section{EXPERIMENT}

Compounds of $\mathrm{Gd}_{3-x} \mathrm{Y}_{x} \mathrm{Co}_{29} \mathrm{Ge}_{4} \mathrm{~B}_{10}(x=0,0.5,1.0,1.5$, and 3.0), $\mathrm{Gd}_{3} \mathrm{Co}_{29} \mathrm{Al}_{4} \mathrm{~B}_{10}$ and $\mathrm{La}_{3} \mathrm{Co}_{29} \mathrm{Ge}_{4} \mathrm{~B}_{10}$ were prepared by arc melting appropriate amounts of $\mathrm{Gd}(99.9 \%), \mathrm{Y}$ (99.9\%), La (99.9\%), Co (99.5\%), Ge (99.999\%), $\mathrm{Al}$ (99.999\%), and B (99.5\%) together in an argon atmosphere. Samples were melted at least four times to ensure homogeneity. They were then wrapped in Ta foil and annealed at $900{ }^{\circ} \mathrm{C}$ in a vacuum for 4 days then cooled slowly to room temperature.

$\mathrm{X}$-ray diffraction measurements were performed at room temperature using a GBC MMA powder X-ray diffractometer and $\mathrm{Cu} \mathrm{K} \alpha$ radiation. Direct current magnetization measurements were carried out in a superconducting quan-

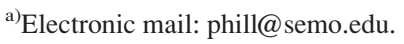

tum interference device (SQUID) magnetometer over the temperature rage of $5-400 \mathrm{~K}$ and in fields of up to $5 \mathrm{~T}$.

\section{RESULTS AND DISCUSSION}

Figure 1 shows x-ray diffraction measurements for representative samples in our system, indicating primarily single phase compounds of the $P 4 / n m m$ tetragonal structure. The lattice parameters were evaluated from the $\mathrm{x}$-ray diffraction patterns using Rietveld profile fit. These are shown in Table I, and match very well with previously published data on the $\mathrm{R}_{3} \mathrm{Co}_{29} \mathrm{M}_{4} \mathrm{~B}_{10}$ systems. ${ }^{3}$ This is a fairly complicated system with two inequivalent rare-earth sites, $7 \mathrm{Co}, 1 \mathrm{Ge}$ or $\mathrm{Al}$, and four B sites, and leads to some interesting magnetic coupling between the rare-earth and cobalt lattices. Because the radius of the $\mathrm{Y}$ ion is very close to that of Gd, the size and geometry of the lattice changes very little as $\mathrm{Y}$ is substituted for $\mathrm{Gd}$.

Magnetization measurements, $M(T)$, at low field $(H=100$ Oe) show that $\mathrm{Gd}_{3} \mathrm{Co}_{29} \mathrm{Ge}_{4} \mathrm{~B}_{10}$ orders ferrimagnetically at $T_{C}=212 \mathrm{~K}$. Then, as the temperature is lowered, magnetization decreases to a compensation point $T_{\text {comp }}=128 \mathrm{~K}$. There is also a small peak in magnetization at $T_{\text {peak }}=94 \mathrm{~K}$. The Y sample $(x=3.0)$ exhibits three magnetic transition temperatures as the temperature is lowered, the first at $T_{C}=189 \mathrm{~K}$ and two smaller ferromagnetic-like transitions at $T=30 \mathrm{~K}$ and $T=21 \mathrm{~K}$. These transitions are not evident in Fig. 2, but show up clearly as inflection points in the slope of $M(T)$, and may signal further magnetic transitions or spin reorientation processes in the sample. In addition, a small downturn in magnetization was noted below about $13 \mathrm{~K}$. Samples with Gd show a small peak in magnetization close to $95 \mathrm{~K}$, which is difficult to see in the $x=0.5$ sample, and is not evident at all in the $\mathrm{Y}$ or $\mathrm{Al}$ (not shown here) samples. Figure 2 shows that in $\mathrm{Gd}_{3-x} \mathrm{Y}_{x-}$ $\mathrm{Co}_{29} \mathrm{Ge}_{4} \mathrm{~B}_{10}$ with $x<3, T_{C}$ remains constant, the temperature 


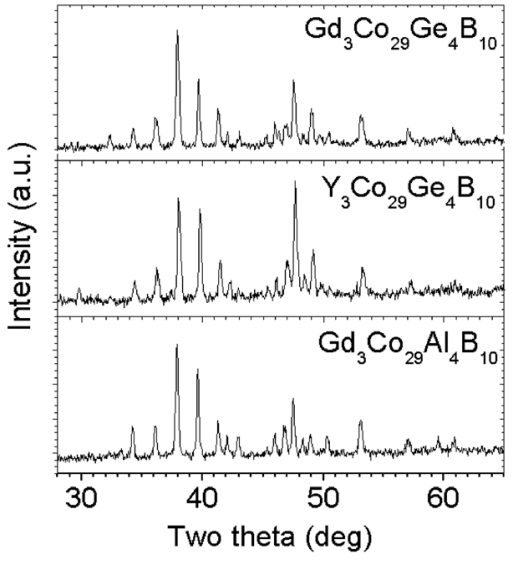

FIG. 1. X-ray data of representative members of the $\mathrm{Gd}_{3} \mathrm{Co}_{29} \mathrm{Ge}_{4} \mathrm{~B}_{10}$ family of compounds showing the predominantly single-phase nature of our samples.

of the compensation point ( $\left.T_{\text {comp }}\right)$ decreases monotonically, and the small peak in magnetization remains constant at about $95 \mathrm{~K}$. This seems to indicate that the ordering at $T_{C}$ is the result of an ordering of the Co moments, because it is not affected by changes on the rare-earth lattice. The small peak at $95 \mathrm{~K}$ also appears to be to the result of a reorientation of a portion of the Co moments. This peak is also observed in samples of $\mathrm{Gd}_{3} \mathrm{Co}_{29} \mathrm{Si}_{4} \mathrm{~B}_{10}$ at about $70 \mathrm{~K},{ }^{7}$ though it is not observed in our $\mathrm{Al}$ sample.

The application of a magnetic field of $5 \mathrm{~T}$ shifts $T_{C}$ to a higher temperature but does not affect $T_{\text {comp. The small peak }}$ at $95 \mathrm{~K}$ is no longer evident. The value of the effective paramagnetic moment ( $\left.p_{\text {eff }}\right)$ as determined from the high temperature dependence of the inverse susceptibility for $\mathrm{Gd}_{3} \mathrm{Co}_{29} \mathrm{Ge}_{4} \mathrm{~B}_{10}$ was found to be $20.0 \mu_{B} /$ f.u. Some of our samples were either not linear in $1 / \chi$ at high temperatures, or we were unable to obtain data at temperatures sufficiently above $T_{C}$, so we were unable to obtain $p_{\text {eff. for all samples. }}$

Magnetization as a function of field (not shown here) shows a similar ferromagnetic type of behavior for all compounds, with the tendency to saturation at high fields. The Y samples show much quicker saturation than the gadolinium ones, and saturate at a higher value, evidence of the influence of antiferromagnetic coupling between the rare-earth and cobalt lattices. By comparing the values of magnetization for $\mathrm{Gd}_{3} \mathrm{Co}_{29} \mathrm{Ge}_{4} \mathrm{~B}_{10}$ and $\mathrm{Gd}_{2} \mathrm{YCo}_{29} \mathrm{Ge}_{4} \mathrm{~B}_{10}$ at $5 \mathrm{~T}$ and $5 \mathrm{~K}$, and assuming that the entire difference is due to the substitution of $\mathrm{Y}$ for $\mathrm{Gd}$, we find that each $\mathrm{Gd}$ contributes $6.28 \mu_{B} / \mathrm{Gd}$,

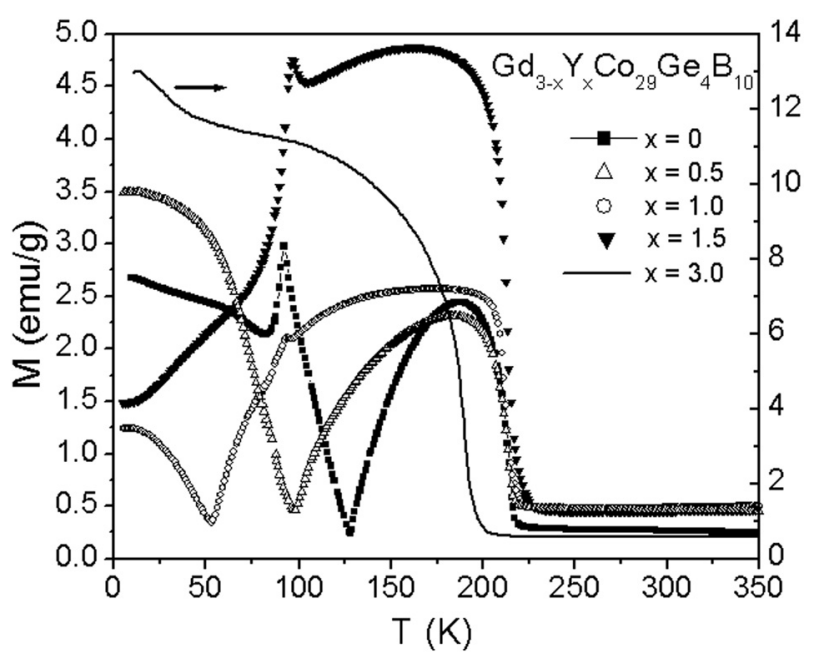

FIG. 2. Magnetization as a function of temperature for $\mathrm{Gd}_{3-x} \mathrm{Y}_{x} \mathrm{Co}_{29} \mathrm{Ge}_{4} \mathrm{~B}_{10}$ at $H=100 \mathrm{Oe}$.

lower than that expected for the $\mathrm{Gd}^{3+}$ ion. Using this value for the moment on $\mathrm{Gd}$ in $\mathrm{Gd}_{3} \mathrm{Co}_{29} \mathrm{Ge}_{4} \mathrm{~B}_{10}$, we obtain a moment of about $0.32 \mu_{B} / \mathrm{Co}$, which is consistent with the values of $0.5 \mu_{B} / \mathrm{Co}$ in $\mathrm{La}_{3} \mathrm{Co}_{29} \mathrm{Si}_{4} \mathrm{~B}_{10}$ (Ref. 1) and $0.4 \mu_{B} / \mathrm{Co}$ in $\mathrm{Nd}_{3} \mathrm{Co}_{29} \mathrm{Si}_{4} \mathrm{~B}_{10}$ (Ref. 2) found from neutron diffraction measurements.

In rare-earth-transition-metal compounds, there are contributions to the magnetic order from the $d-d, f$ - $d$, and $f-f$ exchange interactions. As far as $T_{C}$ is unaffected by the substitution of $\mathrm{Y}$ for the $\mathrm{Gd}$, one can conclude that $d$ - $d$ interaction is the major one in this system, consistent with the theoretical investigations. ${ }^{5}$ Also, as the lattice expands with the substitution of $\mathrm{Al}$ for $\mathrm{Ge}$, the $d$ - $d$ overlap is reduced and the Curie temperature is lowered.

The magnetocaloric effect, in terms of the isothermal magnetic entropy change $(\Delta S)$, has been estimated by employing Maxwell's thermodynamic relation $(\partial S / \partial H)_{T}$ $=(\partial M / \partial T)_{H}$. The values of $\Delta S$ were obtained from the magnetization isotherms, which were measured in fields up to $5 \mathrm{~T}$ at several fixed temperatures. Figure 3(a) shows the temperature dependence of the field-induced entropy change of $\mathrm{Gd}_{3} \mathrm{Co}_{29} \mathrm{Ge}_{4} \mathrm{~B}_{10}$ for several values of the maximum applied field. Though the magnitude of $\Delta S$ is not large, an interesting feature of this alloy is that there are two changes of sign for $\Delta S$ over the temperature range. At high temperature, a peak in $\Delta S$ for all fields can be seen at $215 \mathrm{~K}$, which

TABLE I. A summary of lattice constants and magnetic properties of $\mathrm{Gd}_{3-x} \mathrm{Y}_{x} \mathrm{Co}_{29} \mathrm{Ge}_{4} \mathrm{~B}_{10}$ and $\mathrm{Gd}_{3-x} \mathrm{Y}_{x} \mathrm{Co}_{29} \mathrm{Al}_{4} \mathrm{~B}_{10}$ samples. (Lattice constants were not calculated for all samples.)

\begin{tabular}{|c|c|c|c|c|c|c|c|}
\hline & \multicolumn{3}{|c|}{ Lattice constants } & \multirow[b]{2}{*}{$T_{C}(\mathrm{~K})$} & \multirow[b]{2}{*}{$T_{\text {comp }}(\mathrm{K})$} & \multirow[b]{2}{*}{$T_{\text {peak }}(\mathrm{K})$} & \multirow[b]{2}{*}{$M$ at $5 \mathrm{~T}, 5 \mathrm{~K}\left(\mu_{\mathrm{B}} /\right.$ f.u. $)$} \\
\hline & $a(\AA)$ & $c(\AA)$ & $c / a$ ratio & & & & \\
\hline $\mathrm{Gd}_{3} \mathrm{Co}_{29} \mathrm{Ge}_{4} \mathrm{~B}_{10}$ & 11.2094 & 7.8744 & 0.702 & 212 & 128 & 94 & 9.70 \\
\hline $\mathrm{Gd}_{2.5} \mathrm{Y}_{0.5} \mathrm{Co}_{29} \mathrm{Ge}_{4} \mathrm{~B}_{10}$ & - & - & & 212 & 97 & 87 & - \\
\hline $\mathrm{Gd}_{2} \mathrm{YCo}_{29} \mathrm{Ge}_{4} \mathrm{~B}_{10}$ & 11.2070 & 7.8740 & 0.703 & 211 & 40 & 95 & 3.42 \\
\hline $\mathrm{Gd}_{1.5} \mathrm{Y}_{1.5} \mathrm{Co}_{29} \mathrm{Ge}_{4} \mathrm{~B}_{10}$ & - & - & & 212 & None & 96 & - \\
\hline $\mathrm{Y}_{3} \mathrm{Co}_{29} \mathrm{Ge}_{4} \mathrm{~B}_{10}$ & 11.2053 & 7.8693 & 0.702 & 189 & None & 21 & 27.6 \\
\hline $\mathrm{Gd}_{3} \mathrm{Co}_{29} \mathrm{Al}_{4} \mathrm{~B}_{10}$ & 11.2152 & 7.8731 & 0.702 & 182 & 128 & 121 & 10.70 \\
\hline $\mathrm{Y}_{3} \mathrm{Co}_{29} \mathrm{Al}_{4} \mathrm{~B}_{10}$ & 11.2112 & 7.8717 & 0.702 & 136 & None & None & - \\
\hline
\end{tabular}




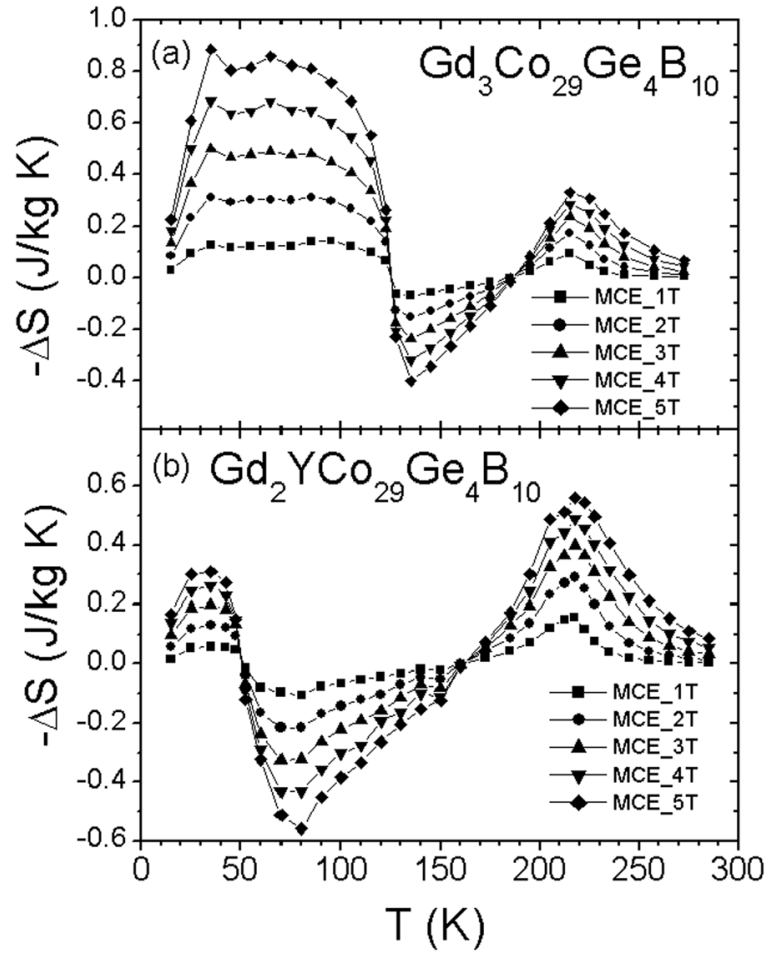

FIG. 3. Field-induced entropy change as a function of temperature at selected values of the maximum applied field for (a) $\mathrm{Gd}_{3} \mathrm{Co}_{29} \mathrm{Ge}_{4} \mathrm{~B}_{10}$, and (b) $\mathrm{Gd}_{2} \mathrm{YCo}_{29} \mathrm{Ge}_{4} \mathrm{~B}_{10}$.

corresponds to $T_{C}$. At $185 \mathrm{~K}$, corresponding to the peak in magnetization as a result of the compensation of the Co moments by $\mathrm{Gd}$ as it begins to order, $\Delta S$ changes sign for the first time. The peak in the negative portion of the graph occurs at around $135 \mathrm{~K}$, which corresponds to an inflection point in the curve as the magnetization decreases toward compensation. At the compensation point, $T_{\text {comp }}=128 \mathrm{~K}$, $\Delta S$ once again changes sign, leading to a broad plateau-like feature in the entropy curves at low temperature. It is an interesting feature of these curves that because the compensation temperature does not shift as a function of field, the $\Delta S$ curves for all applied fields cross at the same point.

Figure 3(b) shows the field induced entropy change for $\mathrm{Gd}_{2} \mathrm{YCo}_{29} \mathrm{Ge}_{4} \mathrm{~B}_{10}$. Substituting $\mathrm{Y}$ for $\mathrm{Gd}$ in this compound changes the magnitudes of $\Delta S$, increasing the magnitudes of the first two peaks, because of ordering of the cobalt and then gadolinium moments, and decreasing the height and range of the low temperature plateau. Changes in the sign of $\Delta S$ move to lower temperatures and still correlate with the same features in low-field magnetization as before.

\section{CONCLUSIONS}

The new magnetic family investigated here, $\operatorname{Gd}_{3-x}$ $\mathrm{Y}_{x} \mathrm{Co}_{29} \mathrm{M}_{4} \mathrm{~B}_{10}(M=\mathrm{Ge}, \mathrm{Al})$ shows complex ferrimagnetic ordering and interesting magnetocaloric behavior as a function of temperature. Substitution of $\mathrm{Y}$ for Gd does not change the Curie temperature, but does shift the compensation point to lower temperatures. This indicates that the substitution of Y for Gd in these samples does not affect the $d$ - $d$ exchange interaction, but has a pronounced effect on the $f-d$ exchange interaction. Even though the entropy change for applied fields of $1-5 \mathrm{~T}$ is not large, it exhibits two changes of sign as the temperature is lowered, as a result of the compensation of the Gd and Co moments. Recent studies have shown that quite a few combinations of the rare-earth, transition-metal, and metalloid atoms form stable compounds of this structure; ${ }^{1}$ so by changing the constituents of this material, it may be possible to increase the magnetic entropy change and tune the transition temperatures to produce useful magnetic materials.

\section{ACKNOWLEDGMENTS}

This work is partly supported by the U.S. Department of Energy (Grant No. DE-FG02-06ER46291).

${ }^{1}$ H. Zhang, M. Hofmann, S. J. Kennedy, and S. J. Campbell, Mater. Res. Soc. Symp. Proc. 804, JJ3.4.1 (2004).

${ }^{2}$ H. Zhang, M. Hofmann, S. J. Kennedy, and S. J. Campbell, J. Appl. Phys. 97, 10M502 (2005).

${ }^{3}$ H. Zhang, S. J. Campbell, H.-S. Li, and E. Wu, J. Alloys Compd. 284, 155 (1999).

${ }^{4}$ H. Zhang, S. J. Campbell, and A. V. J. Edge, J. Phys.: Condens. Matter 12, L159 (2000).

${ }^{5}$ H. Zhang and S. J. Campbell, J. Appl. Phys. 93, 9177 (2003).

${ }^{6}$ H. Zhang, E. Wu, S. J. Campbell, S. J. Kennedy, H.-S. Li, A. J. Studer, S. R. Bulcock, and A. D. Rae, J. Alloys Compd. 278, 239 (1998).

${ }^{7}$ H. Zhang, S. J. Campbell, H.-S. Li, Q. W. Yan, E. Wu, and M. Hoffmann, Physica B 305, 10 (2001). 